\title{
CES
}

COOPERATIVISMO E ECONOMÍA SOCIAL

Núm. 40 (2017-2018), páxs. 261-267

ISSN: 1130-2682

\section{ESPECIFICIDADES DO DIREITO DE DEMISSÃO NAS COOPERATIVAS DE HABITAÇÃO. ANOTAÇÃO AO ACÓRDÃO DO TRIBUNAL DA RELAÇÃO DE LISBOA DE 9 DE NOVEMBRO DE 2017}

\section{SPECIFICITIES OF THE DUTY OF WITHDRAWAL IN HOUSING COOPERATIVES. NOTES TO THE JUDGEMENT OF THE

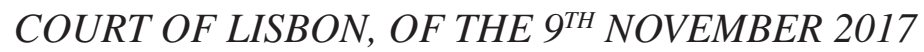

\author{
Deolinda Meira*
}

\footnotetext{
* Professora Adjunta do Instituto Politécnico do Porto/ISCAP/CEOS.PP. Correio eletrónico: meira@ iscap. ipp. pt. Correio postal: Instituto Superior de Contabilidade e Administração do Porto, Rua Jaime Lopes de Amorim, 4465-004 S. Mamede de Infesta, PORTUGAL.
} 



\section{O LiTíGIO}

$\mathrm{E}$

m 1998, a Autora tornou-se membro de uma cooperativa de habitação, tendo pago a taxa de inscrição e as quotas mensais. Em 2012 e 2013, a Autora subscreveu dois acordos de transferência de posição entre cooperativas, o último dos quais para a Ré, o qual incluía uma cláusula prevendo as condições de desistência do programa habitacional. Especificamente, o art. 8. ${ }^{\circ}$, n. $^{\circ}$ 4, dos Estatutos da Ré, tem o seguinte teor: "Aos membros excluídos ou demitidos serão restituídos no prazo máximo os títulos de capital realizados. Outros valores aplicados a que tiverem direito até à data da sua exclusão ou demissão serão liquidados logo que a Cooperativa encontre um cooperador substituto." Acresce que, do referido acordo de transferência de posição celebrado entre a Autora e a Ré, constava uma cláusula (cláusula 4. ${ }^{\text {a) }}$ que condicionava o reembolso dos títulos de participação à existência de um cooperador substituto ou ao preenchimento do lugar da Autora por outro cooperador suplente ou, na sua ausência, por cooperador indicado pela Autora, e após este realizar a totalidade da quantia a restituir.

De 1998 a 2013, a Autora realizou entregas no valor global de 35.299,24 EUR às duas anteriores cooperativas, integralmente transferidos para a Ré. Em 26 de fevereiro de 2015, a Autora comunicou à Ré a sua desistência de cooperadora, mas nunca lhe foram restituídos os títulos de participação entregues, no valor de 18.000,00 EUR.

A Ré apresentou os seguintes fundamentos para a recusa: (i) a validade dos seus estatutos, os quais foram registados na Cooperativa António Sérgio para a Economia Social (CASES), sem que esta entidade tenha questionado a validade dos mesmos; (ii) a validade da cláusula do acordo de transferência de posição; (ii) a Autora nunca lhe entregou qualquer quantia; (iii) a Autora apenas detinha um potencial crédito que seria descontado ao preço final do fogo que resolvesse adquirir.

O Tribunal de primeira instância julgou a ação improcedente, com fundamento em abuso de direito por parte da Autora, com a consequente absolvição da Ré dos pedidos. Concretamente, o Tribunal de primeira instância chegou à conclusão de que a Autora excedeu manifestamente os limites da boa-fé ao provocar a confiança da Ré na "manutenção da situação jurídica”, ou seja, na não exigência dos títulos em conformidade com o que ficara contratualmente estabelecido no acordo de transferência celebrado entre ambas. Não obstante, o Tribunal considerou feridos de nulidade o mencionado art. 8. ${ }^{\circ}$, n. $^{\circ} 4$, dos Estatutos da Ré, bem como a cláusula $4 .^{a}$ do acordo de transferência, por violarem o art. $24 .^{\circ}$ do Regime Jurídico das Cooperativas de Habitação e Construção, que prevê o reembolso sem 
condicionantes (a não ser pagamento em prestações previsto nos estatutos) dos títulos de participação.

Inconformada, a Autora interpôs recurso desta decisão para o Tribunal da Relação de Lisboa, o qual proferiu um Acórdão, em 9 de novembro de 2017, que julgou o recurso procedente.

Invoca o Tribunal da Relação de Lisboa que o art. $36^{\circ}$, n. $^{\circ} 3$, do Código Cooperativo, aprovado pela L. n. ${ }^{\circ}$ 51/96, de 7 de setembro, aplicável por remissão do n. ${ }^{\circ} 1$ do art. $24 .^{\circ}$ do Regime Jurídico das Cooperativas de Habitação (DL n. ${ }^{\circ}$ $502 / 99$, de 19 de novembro), previa a restituição ao cooperador que se demitisse do montante dos títulos de capital realizados segundo o seu valor nominal "no prazo estabelecido pelos estatutos ou, supletivamente, no prazo máximo de um ano".

É sobre este Acórdão do Tribunal da Relação de Lisboa que nos iremos debruçar nesta Anotação.

Dado que o Acórdão em comentário decidiu o litígio à luz das normas jurídicas constantes do já revogado Código Cooperativo de 1996 (L. n. ${ }^{\circ}$ 51/96, de 7 de setembro), será à luz de tais disposições que também será desenvolvida a anotação ${ }^{1}$.

\section{ANOTAÇÃO}

A questão fulcral discutida neste Acórdão prende-se com o regime jurídico do direito de demissão e consequente direito ao reembolso numa cooperativa de habitação, nomeadamente a questão de saber da admissibilidade de estabelecer condicionantes a estes direitos.

Nesta anotação procuraremos responder às duas questões centrais do Acórdão: (i) A demissão da Autora da qualidade de membro da Cooperativa - Ré constitui esta na obrigação de devolução imediata dos valores entregues pela Autora, a título de poupanças obrigatórias? (ii) Será possível o diferimento da devolução desse valor para o momento da rentabilização do programa ou para momento em que outro cooperador ocupe o seu lugar ou por substituição de um novo cooperador que ocupe o seu lugar?

\subsection{O direito subjetivo de demissão: fundamentos e consequências}

O direito de demissão é um direito subjetivo dos cooperadores, o qual constitui uma especificidade do regime jurídico das cooperativas.

Este direito é uma das manifestações do princípio cooperativo da adesão voluntária e livre (art. 3..$^{\circ}$ do CCoop). Na verdade, este princípio relaciona-se não apenas com a adesão de cooperadores (art. 31. ${ }^{\circ}$ do CCoop) mas também com a

\footnotetext{
1 - Em 30 de setembro de 2015, entrou em vigor o atual Código Cooperativo (L. n. ${ }^{\circ}$ 119/2015, de 31 de agosto).
} 
saída destes da cooperativa. Ao abrigo deste princípio cooperativo reconhece-se ao cooperador a liberdade de se demitir da cooperativa em qualquer momento e por sua iniciativa.

A liberdade de o cooperador se demitir da cooperativa conflitua com o interesse da cooperativa em não ver diminuído o seu número de membros e, consequentemente, o seu capital social, pois a demissão do cooperador tem como consequência económica o reembolso da sua entrada de capital (art. $36 .^{\circ}$, n. $^{\circ} 3$, do CCoop). Acresce que a demissão do cooperador da cooperativa poderá implicar uma diminuição do volume da atividade económica desenvolvida com os cooperadores, no quadro da relação mutualista (Gemma Fajardo-García, La gestión económica de la cooperativa: responsabilidade de los socios, Tecnos, Madrid, 1997, pág. 236).

Neste contexto, e de forma a conseguir a conciliação entre estes interesses, o legislador permite que se consagrem regras estatutárias: que difiram o pagamento das prestações a que tenham direito os cooperadores que se demitam; que condicionem a saída a um aviso prévio ou a limites epocais, no decurso de cada ano; ou que estabeleçam que o direito de demissão só poderá ser exercido depois de decorrido um certo número de anos sobre a data da adesão.

Estas regras e condições para o exercício do direito de demissão, previstas estatutariamente (art. 15. ${ }^{\circ},{ }^{\circ}{ }^{\circ}$ 2, al. a), do CCoop), poderão limitar, mas nunca suprimir, o direito de demissão, pois só assim se respeita o princípio cooperativo da adesão voluntária e livre (art. 3. ${ }^{\circ}$ do CCoop).

\subsection{O condicionamento estatutário do direito de demissão}

$\mathrm{O}$ art. $36^{\circ}$, n. ${ }^{\circ}$ 1, do CCoop, estabelece que os cooperadores podem solicitar a sua demissão, nas condições estabelecidas nos estatutos ou, no caso de estes serem omissos, no fim de um exercício social, com pré-aviso de 30 dias.

Entre as condições de demissão previstas estatutariamente destaca-se a possibilidade de estabelecer prazos mínimos de permanência, que constam, inclusivamente, de alguns diplomas aplicáveis aos ramos cooperativos relativos ao crédito, ao setor agrícola e à habitação, tal como veremos.

Note-se que esta possibilidade de exigir, estatutariamente, prazos mínimos de permanência relaciona-se, sobretudo, com a obrigação de participação do cooperador na atividade da cooperativa (art. $34 .^{\circ},{ }^{\circ} .^{\circ}$ 2, al. c), do CCoop). Efetivamente, quando o cooperador se demite da cooperativa deixa de estar obrigado a participar na referida atividade, o que poderá implicar uma redução da capacidade económica da mesma.

Por este motivo, e tendo em conta o quadro da relação mutualista que une o cooperador e a cooperativa, o legislador concede às cooperativas duas possibilida- 
des que garantam essa capacidade económica: (i) permitir que a cooperativa exija estatutariamente a permanência dos cooperadores por determinados períodos de tempo; (ii) permitir que as obrigações relacionadas com a atividade económica da cooperativa possam estender-se para além da relação cooperativa, ou seja, apesar da saída do cooperador, este será obrigado ao cumprimento da atividade económica a que se comprometeu (Gemma Fajardo-García, La gestión económica de la cooperativa: responsabilidade de los sócios, cit., pág. 236; e Deolinda APARÌCIO Meira, O regime económico das cooperativas no Direito Português: o capital social, Vida Económica, Porto, 2009, págs. 124 e ss).

Esta extensão da relação mutualista, para além da relação cooperativa, dá-se nas cooperativas de habitação.

A participação na atividade económica neste tipo de cooperativas implica a entrega de fundos necessários para a construção da habitação. Ora, o art. $24 .^{\circ}$ do DL n. ${ }^{\circ}$ 502/99, de 19 de novembro, estabeleceu que, nas cooperativas de habitação e construção, o cooperador, em caso de demissão ou exclusão, terá direito ao reembolso previsto no CCoop (reembolso dos títulos de capital), acrescido do valor dos títulos de participação realizados para amortização da habitação, com os respetivos juros. Acrescentou, ainda, que os estatutos poderão prever que tal reembolso se faça em prestações, com ou sem juros. Contudo, "em caso algum serão reembolsadas as quantias pagas a título de preço do direito de habitação". Esta proibição deverá ser interpretada no sentido de que a cooperativa reterá essas quantias até que outra pessoa (um cooperador suplente ou um novo cooperador) ingresse na posição do cooperador cessante. Enquanto tal não acontecer ou se não acontecer, a cooperativa ficará com os montantes já prestados pelo cooperador desistente.

Esta é a solução adotada na Ley Estatal de Cooperativas espanhola, no seu art. $89 .^{\circ}, \mathrm{n}^{\circ} 5$, ao estabelecer que os montantes entregues pelo cooperador para financiar o pagamento das habitações deverão ser reembolsados no momento em que seja substituído, nos seus direitos e obrigações, por outro cooperador.

No Acórdão do Tribunal da Relação de Lisboa, de 26 de setembro de 2017 (Processo n. ${ }^{\circ}$ 464/13.2TJLSB.L1-1), afirma-se que: "I. - As posições jurídicas decorrentes da participação em programa habitacional de cooperativa de habitação, porque do domínio da atividade cooperativa e não do domínio da pura atividade comercial de construção e venda de imóveis, regulam-se pelo Código Cooperativo e legislação complementar; II. - A adesão a um projeto habitacional importa uma adesão firme, não sendo a desistência individual causa de exoneração das responsabilidades assumidas nem da restituição do já prestado". Neste Acórdão refere-se, ainda, que, em caso de demissão do cooperador (que desiste, por isso, do programa habitacional), a não restituição dos quantitativos já prestados pelo desistente (que até já poderão ter sido utilizados na realização de despesas inerentes ao programa) não configura um enriquecimento sem causa. Afirma-se, no ci- 
tado Acórdão, que "Esse enriquecimento só se poderá concretizar a final aquando da liquidação do projeto habitacional. Só na medida em que o projeto habitacional tenha logrado ultrapassar os efeitos negativos da desistência, cobrindo o prejuízo daí adveniente, é que haverá, verdadeiramente, um enriquecimento do projeto habitacional à custa do desistente".

$\mathrm{Na}$ mesma linha, nas cooperativas agrícolas, o legislador permite que estas estabeleçam nos estatutos "condicionamentos às demissões dos cooperadores, tendo em conta o respeito e o cumprimento de compromissos, nomeadamente financeiros, assumidos pela cooperativa durante o período de vinculação desse cooperador" (art. 8. ${ }^{\circ}$ do DL n. ${ }^{\circ} 335 / 99$, de 20 de agosto). Entre estes condicionamentos inclui-se o estabelecimento de um período mínimo de permanência na cooperativa. Pretender-se-á, deste modo, compatibilizar o direito do cooperador a demitir-se da cooperativa com a necessidade de esta conhecer e manter a sua capacidade económica.

Destaquem-se, ainda, as cooperativas de crédito para as quais o legislador estabeleceu um prazo mínimo de permanência de, pelo menos, três anos, a contar da adesão do cooperador ${ }^{2}$, permitindo, assim, ao órgão de administração suspender o reembolso se este for suscetível de causar problemas graves à cooperativa ${ }^{3}$ ou condicionar a eficácia da exoneração à prévia satisfação pelo cooperador de todos os seus compromissos para com a cooperativa ${ }^{4}$.

\section{A DECISÃO}

Com este enquadramento, e face aos factos vertidos no Acórdão, não acompanhamos o entendimento de que as cláusulas de demissão previstas quer nos Estatutos da Ré quer no acordo de transferência de posição preveem condições de reembolso contrárias à legislação cooperativa.

Sendo assim, a demissão da Autora da qualidade de membro da Cooperativa Ré não constitui esta na obrigação de devolução imediata dos valores entregues pela Autora, a título de poupanças obrigatórias, sendo possível o diferimento da devolução desse valor para o momento da rentabilização do programa ou para momento em que outro cooperador ocupe o seu lugar o por substituição de um novo cooperador que ocupe o seu lugar.

\footnotetext{
2 - Neste sentido, refiram-se os arts. $17 .^{\circ}$, n. ${ }^{\circ} 3$, al. b) e $68 .^{\circ}$, n. ${ }^{\circ} 1$, do Regime Jurídico do Crédito Agrícola Mútuo (DL n. ${ }^{\circ} 24 / 91$, de 11 de janeiro).

3 - V. o art. 17. ${ }^{\circ}$ n. ${ }^{\circ}$ 4, al. a), do Regime Jurídico do Crédito Agrícola Mútuo.

4 - V. o art. 68. ${ }^{\circ}$, n. ${ }^{\circ}$ s e 4, do Regime Jurídico do Crédito Agrícola Mútuo.
} 